\title{
Acute appendicitis after liver transplantation: A single center experience and review of the literature
}

\author{
Indah Jamtani*, Sara Kim*, Jeong-Moo Lee, Kwang-Woong Lee, Suk Kyun Hong, \\ Kwangpyo Hong, Eui Soo Han, Nam-Joon Yi, and Kyung-Suk Suh
}

Department of Surgery, Seoul National University College of Medicine, Seoul, Korea

\begin{abstract}
Backgrounds/Aims: Acute appendicitis is one of the most common emergent disease in the general population requiring surgical treatment. However, only a few cases of appendicitis after liver transplantation (LT) were reported. We described experiences of acute appendicitis after LT in single center. Methods: From March 1988 to July 2019, we reviewed retrospectively all the patients who diagnosed with acute appendicitis after LT at the Seoul National University Hospital. We described and analyzed clinical outcomes of appendectomy after LT. Results: A total of 12 patients out of 2,237 LT patients underwent appendectomy due to acute appendicitis. The mean age was $48 \pm 12$ years. Nine patients $(75 \%)$ underwent deceased donor liver transplantation (DDLT) and three patients $(25 \%)$ underwent living donor liver transplantation (LDLT). The mean days from transplantation to the onset of acute appendicitis was 739 (range 57-4,496) days. Every patients underwent appropriate appendectomy within 1 days after visiting hospital. Leukocytosis was seen in three patients (25\%). Seven patients (58\%) underwent laparoscopic appendectomy and five patients (42\%) underwent open appendectomy. The total operative time was 47.5 (range 25-135) minutes. The median postoperative hospitalization was 4 (range 2-11) days. There was no postoperative complications documented. There was no significant difference of clinical outcomes between laparoscopic appendectomy group and open appendectomy group. Conclusions: Early surgical management achieved satisfactory postoperative results without graft dysfunction after LT. Laparoscopic appendectomy also could be applicable with safe and feasible outcomes even in post-LT recipients. (Ann Hepatobiliary Pancreat Surg 2020;24:44-51)
\end{abstract}

Key Words: Acute appendicitis; Liver transplantation; Laparoscopy; Appendectomy

\section{INTRODUCTION}

Acute appendicitis is one of the most frequent emergent disease requiring surgical treatment. However, reports on acute appendicitis in liver transplantation (LT) recipient remains scanty.

The increasing number of liver transplantation and improvement in survival rate also increases the incidence of various intra-abdominal surgical emergencies. ${ }^{1-4}$

The diagnosis and management of acute appendicitis in transplanted patients follow the principles of any surgical emergencies. However, compared to the general population, the fact that transplanted patients are always in an immunosuppressive state should always in considered. Pre- vious studies have reported that acute appendicitis after LT may present different clinical courses and thus, may result in more perioperative complications. Therefore, early diagnosis and surgery is crucial in managing LT patients with long-term immunosuppressive therapy. ${ }^{3-6}$

An open approach is usually recommended in abdominal emergencies in post-transplant patients. However, with the advancement of instruments and improvement in surgeons' skills, laparoscopic approach has recently performed and showed to be feasible. ${ }^{2,4,7,8}$ In this study, we report a single center experience acute appendicitis after liver transplantation.

Received: October 15, 2019; Revised: November 14, 2019; Accepted: November 14, 2019

Comesponding author: Jeong-Moo Lee

Department of Surgery, Seoul National University College of Medicine, 101 Daehak-ro, Jongno-gu, Seoul 03080, Korea

Tel: +82-2-2072-2817, Fax: +82-2-766-3975, E-mail: 1ulu5050@naver.com

*Indah Jamtani and Sara Kim contributed equally to this work as co-first authors.

Copyright (C) 2020 by The Korean Association of Hepato-Biliary-Pancreatic Surgery

This is an Open Access article distributed under the terms of the Creative Commons Attribution Non-Commercial License (http://creativecommons.org/ licenses/by-nc/4.0) which permits unrestricted non-commercial use, distribution, and reproduction in any medium, provided the original work is properly cited. Annals of Hepato-Biliary-Pancreatic Surgery • pISSN: 2508-5778 - elSSN: 2508-5859 


\section{MATERIALS AND METHODS}

Data from March 1988 to July 2019, we reviewed retrospectively all the patients who diagnosed with acute appendicitis after LT at the Seoul National University Hospital. Total 2,237 cases of LT were formed at the SNUH. 1,551 patients underwent living donor liver transplantation (LDLT) and the other 686 patients underwent deceased donor liver transplantation (DDLT). Total 12 patients diagnosed with acute appendicitis after LT were selected. Clinical variables including gender, age at transplantation and appendectomy, presenting signs and symptoms, diagnostic evaluations including white blood cell counts and radiology, time to treatment after symptom presentation, surgical methods (laparoscopy versus open surgery), intraoperative findings, intraoperative and postoperative complications, pathological results, postoperative hospital stay and follow-up was collected for analysis.

This study was approved by the Institutional Review Board (IRB) of the Seoul National University Hospital (IRB no. 1909-140-1066) which waived the need for informed consent.

\section{Statistical analysis}

Statistical analysis was performed using SPSS version 25.0 (IBM Corp., Armonk, NY, USA). Continuous data were compared using the Mann-Whitney U-test and categorical data were compared by using the chi-square test or Fisher's exact test. Unpaired t-test was performed to compare the operation time and postoperative hospitalization days between open and laparoscopic appendectomy. $p<0.05$ was considered statistically significant.

\section{RESULTS}

\section{Demographics}

The clinical characteristics of the 12 patients who underwent appendectomy are presented in Table 1. A total of 2,237 LTs were performed from March 1988 to July 2019. 12 patients underwent appendectomy due to acute appendicitis. The mean age of these patients upon presentation was $48 \pm 12$ years. The mean age at liver transplantation of the patients who underwent appendectomy was $45 \pm 11$ years. There were seven $(58 \%)$ male patients and five $(42 \%)$ female patients. Nine $(75 \%)$ patients un- derwent DDLT and three (25\%) patients underwent LDLT. The median days from transplantation to the diagnosis of appendicitis were 739 days (range 57-4,496 days) (Table 2). The median follow-up periods after appendectomy were 1,712 days (range 83-6,566 days).

\section{Presentation and diagnostic evaluation}

All of the 12 patients had preoperative symptoms, including nausea, vomiting, abdominal discomfort, and fever. Local tenderness on the RLQ was observed in all 12 patients. Leukocytosis defined as white blood cell (WBC) counts exceeding $10,000 / \mu \mathrm{L}$ was only seen in three $(25 \%)$ patients. All patients underwent abdominal computed tomography (CT) scan to confirm the diagnosis (Tables 1, 2).

\section{Surgery}

All patients were underwent appendectomy within the median of one day (range 1-3 days) after symptom presentation. Although the open approach is considered safer in post-transplant patients, seven $(58 \%)$ patients at the SNUH underwent laparoscopic compared to the open counterpart $(n=5,42 \%)$. The median operative time was 47.5 minutes (range 25-135 minutes). The mean operative time was $42 \pm 16$ minutes in open group and $64 \pm 37.5$ minutes in laparoscopic appendectomy, but it was not significant different between the two groups $(p>0.05)$. Intra-abdominal drain was placed in seven $(58 \%)$ patients during surgery (Tables 1, 2).

\section{Hospital course and outcome}

The median postoperative length of stay was four days (range 2-11 days) with no surgery-related complications and mortality. The postoperative hospitalized was $4 \pm 2$ days and $5 \pm 3$ days in the open and laparoscopic appendectomy respectively. There was no significant difference between the two groups $(p>0.05)$. Three patients died during longterm follow-up due to recurrence of the primary liver disease. The long-term survival after appendectomy was $75 \%$ (Table 3).

\section{Pathological findings}

Postoperative pathology results showed a high percentage of acute suppurative appendicitis $(n=8,66.7 \%)$. There were three $(25 \%)$ cases of periappendiceal abscess and one $(8.2 \%)$ case of perforation. Acute gangrenous appen- 


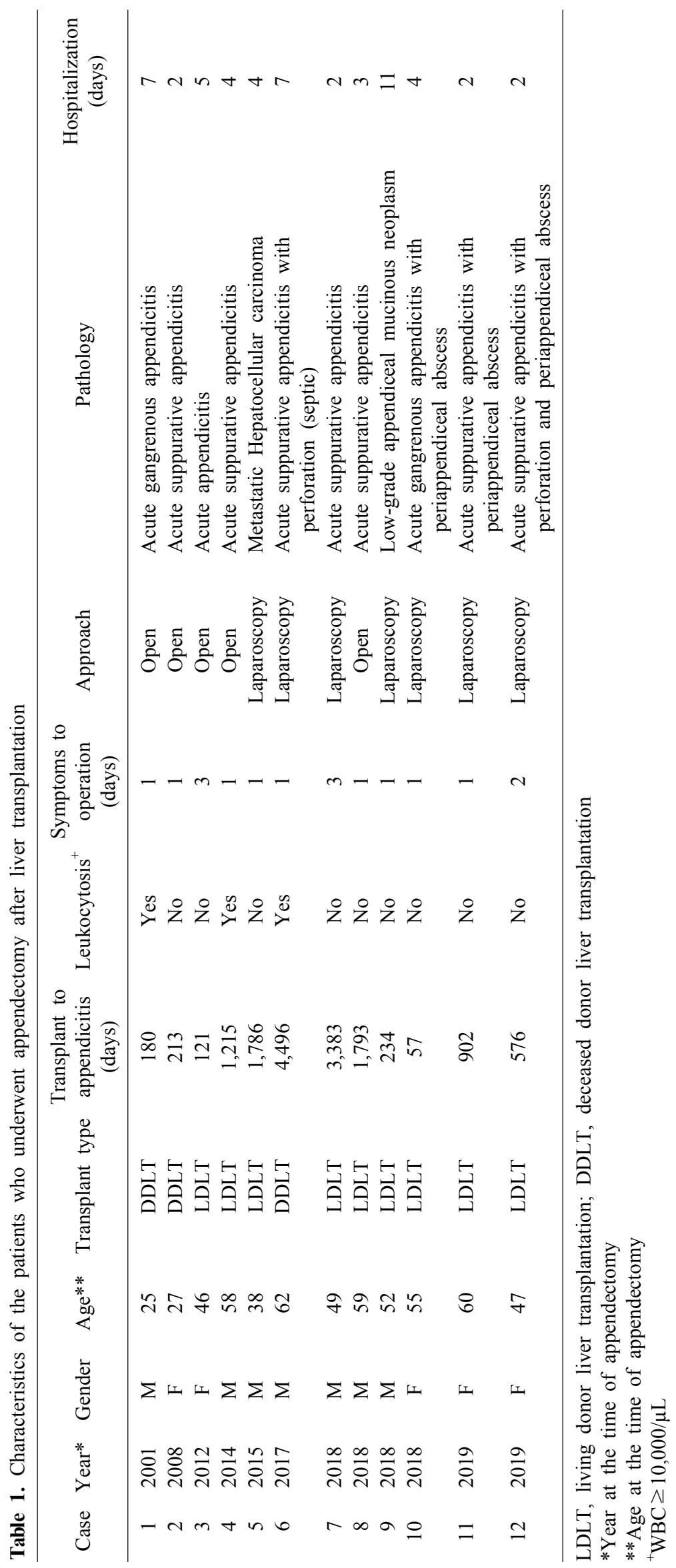


Table 2. Demographic findings of appendicitis in post liver transplant patients

\begin{tabular}{|c|c|}
\hline Variable & Value \\
\hline Age upon presentation, years, median (range) & $50.5(25-62)$ \\
\hline Age at transplantation, years, median (range) & $48(25-57)$ \\
\hline Transplant to appendicitis, days, median (range) & $739(57-4,496)$ \\
\hline \multicolumn{2}{|l|}{ Gender, number $(\%)$} \\
\hline Male & $7(58 \%)$ \\
\hline Female & $5(42 \%)$ \\
\hline \multicolumn{2}{|l|}{ Transplant, number (\%) } \\
\hline DDLT & $9(75 \%)$ \\
\hline LDLT & $3(25 \%)$ \\
\hline Pre-operative symptoms, number (\%) & $12(100 \%)$ \\
\hline \multicolumn{2}{|l|}{ Leukocytosis $(\mathrm{WBC}>10,000 / \mu \mathrm{L})$} \\
\hline Yes & $3(25 \%)$ \\
\hline No & $9(75 \%)$ \\
\hline Preoperative CT scan for diagnosis, number (\%) & $12(100 \%)$ \\
\hline \multicolumn{2}{|l|}{ Surgical approach, number $(\%)$} \\
\hline Open & $5(42 \%)$ \\
\hline Laparoscopic & $7(58 \%)$ \\
\hline Operative time, min, median (range) & $47.5(25-135)$ \\
\hline Open approach, min, median (range) & $40(25-65)$ \\
\hline Laparoscopic approach, min, median (range) & $60(30-135)$ \\
\hline Postoperative hospitalization, days, median (range) & $4(2-11)$ \\
\hline Overall survival, $\%$ & $75 \%$ \\
\hline \multicolumn{2}{|l|}{ Pathology, number (\%) } \\
\hline Acute appendicitis & $1(8.3 \%)$ \\
\hline Acute gangrenous appendicitis & $1(8.3 \%)$ \\
\hline Acute suppurative appendicitis & $8(66.7 \%)$ \\
\hline Metastatic HCC & $1(8.3 \%)$ \\
\hline Low-grade appendiceal mucinous neoplasm & $1(8.3 \%)$ \\
\hline
\end{tabular}

LDLT, living donor liver transplantation; DDLT, deceased donor Liver transplantation; WBC, white blood cell; CT, computed tomography; SD, standard deviation

Table 3. Comparison of postoperative outcomes between open versus laparoscopic appendectomy

\begin{tabular}{lccc}
\hline \multicolumn{1}{c}{ Variable } & Open & Laparoscopy & $p$-value \\
\hline Total, number (\%) & $5(42 \%)$ & $7(58 \%)$ & \\
Transplant to appendectomy, days, median (range) & $213(121-1,793)$ & $902(57-4,496)$ & 0.284 \\
Operative time, min, median (range) & $40(25-65)$ & $60(30-135)$ & 0.244 \\
Postoperative hospitalization, days, median (range) & $4(2-7)$ & $4(2-11)$ & 0.830 \\
Complications, number (\%) & 0 & 0 & \\
Open conversion, number (\%) & - & 0 & \\
\hline
\end{tabular}

$\mathrm{SD}$, standard deviation

dicitis and acute appendicitis were seen in one patient each $(8.3 \%)$. Unusually, one patient had metastatic hepatocellular carcinoma (HCC) in pathologic result of appendix and died due to disease progression. In addition, one patient was diagnosed with low-grade appendiceal mucinous neoplasm (Tables 1, 2).

\section{DISCUSSION}

The number of LT and long-term survival has been increasing and improving accompanied by improved surgical techniques and immunosuppressant. In the last decade, the number of LT has increased exponentially in South Korea. Since the first LT performed in 1988, more than 10,000 cases of LT have been performed in 40 different 


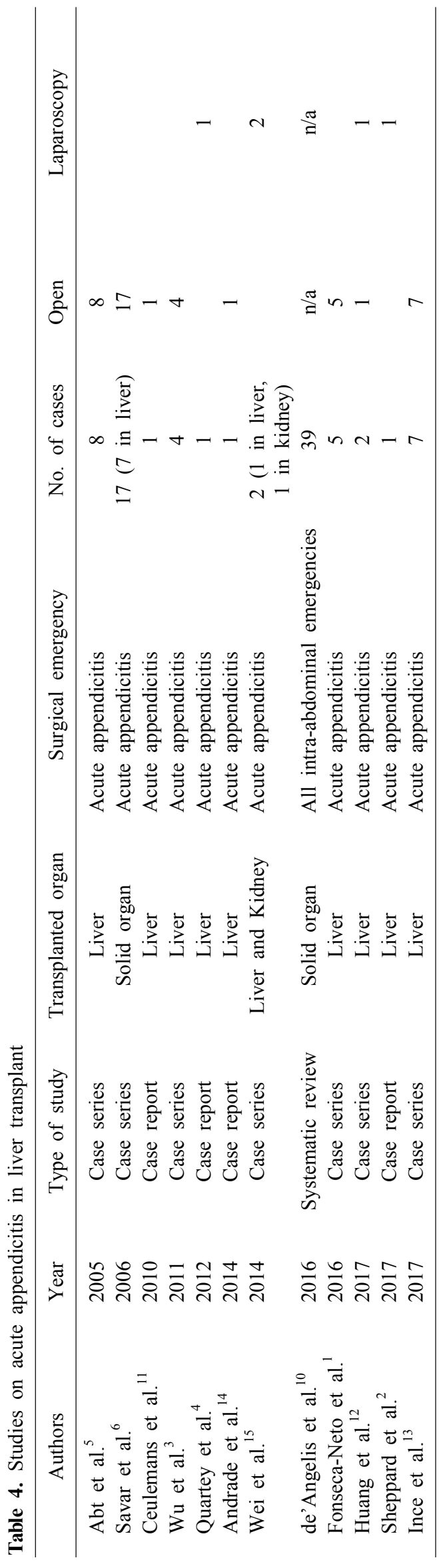

centers. $^{6,9,10}$ With increasing numbers of LT recipients, surgeons should be more cautious in assessing and managing both medical and surgical non-graft related diseases including acute appendicitis.

Acute appendicitis is one of the most common emergent diseases requiring surgical treatment. ${ }^{10}$ However, only few case studies on acute appendicitis in LT recipients have been reported. In this study, 12 patients who underwent LT diagnosed with acute appendicitis were analyzed. This is the largest study on acute appendicitis in LT patients to date. Previous studies regarding this subject are reported as case reviews or series. Although Savar et al. ${ }^{6}$ reported 12 patients in organ transplant recipients diagnosed with acute appendicitis, this study only included seven LT recipients. Furthermore, de'Angelis et al. ${ }^{10}$ performed a systematic review of 39 case series which provided data from mixed abdominal non-graft related emergencies in solid organ transplantation patients. In addition, other studies on acute appendicitis in post-LT patients are mostly case reviews or include less than ten cases (Table 4)..$^{1-5,11-15}$

The reported accumulative incidence of acute appendicitis after $\mathrm{LT}$ in recent studies showed to be less than $0.5 \%{ }^{1-4,10}$ Some report addressed that the incidence of acute appendicitis in LT recipients as $0.09 \%$ and $0.2 \%$ respectively. ${ }^{5,6}$ Similar to the reported and generally accepted incidence, the rate of acute appendicitis in LT patients at the SNUH was $0.5 \%(n=12)$.

In this study, LT patients diagnosed with acute appendicitis presented with similar symptoms of acute appendicitis as the general population. The most prominent symptom and sign was abdominal discomfort and pain with local tenderness at the right lower quadrant (RLQ). All 12 patients showed signs of inflammation at the RLQ. Leukocytosis defined as WBC counts exceeding 10,000/ $\mu \mathrm{L}$ was shown in the majority of their patients in previous studies. ${ }^{5,7}$ However, Leukocytosis as only observed in $25 \%$ of the patients in this study but increased proportion of segmented neutrophil count was observed in almost all cases. This might be related with long-term use of immunosuppressant that sometimes cause leukopenia in post-LT patients. In addition, four out of the twelve patients in this series was on combined immunosuppressant therapy with mycophenolate mofetil (MMF), which is an anti-proliferative drug, at the time of the appendectomy. 
This manifestation is similar with neutropenic enterocolitis in immunocompromised patients. ${ }^{17}$ LT patients presenting signs and symptoms of acute appendicitis can be mistaken as other graft-related complications of misled by other gastrointestinal disease due to immunosuppression. This can lead to delayed diagnosis or even misdiagnosis and consequently delay treatment. Thus, high index of suspicion is always required. Therefore, radiological diagnosis in highly suspicious patients is highly recommended. In most clinical settings, computed tomography (CT) is considered more sensitive and specific in diagnosis acute appendicitis compared to ultrasonography. The sensitivity and specificity of CT scans are $90 \%$ and $91 \%$ respectively in the diagnosis of acute appendicitis. ${ }^{16,18}$ All 12 patients in this study underwent CT scans and showed appendiceal inflammation and wall thickening suggestive of acute appendicitis.

Recently, antibiotics as a non-operative treatment has been popularized in the selected patients in the general population with a $38 \%$ risk of recurrence. However, aggressive management is preferred and recommended to minimize morbidity due to the chronic immunosuppressed status of LT patients. ${ }^{16}$ Early surgical management performed within one to three days after onset of acute appendicitis provided the best results. Appendiceal perforation generally occurs within 48-72 hours and even earlier in immunocompromised patients. ${ }^{19}$ In this study, all 12 patients promptly underwent appendectomy, generally within one day after symptom presentation.

The advantages of the laparoscopic approach are less postoperative pain, shorter hospital stay, and better quality of life in the early and late postoperative period making it a popular choice of approach for patients and surgeons. However, open surgery has been strongly recommended in various abdominal emergencies in LT patients due the possibility of graft-related emergencies and the risk of adhesions. ${ }^{10}$ The main concerns of laparoscopic surgery in patients with previous intra-abdominal surgeries is accessing the abdominal cavity without causing other vascular or organ injuries since appropriate surgical fields may not be obtained due to unpredictable adhesions. However, with the advancement of laparoscopic instruments and improved surgeon's surgical skills and knowledge, laparoscopic surgery has become safer and more feasible in patients who underwent previous abdominal surgeries. ${ }^{7,8}$
This also includes patients who underwent solid organ transplantations. For instance, safe access to the abdominal cavity can be gained by utilizing the Hasson open technique for the first trocar that can provide safe access for additional trocars. ${ }^{8}$

The proportion of laparoscopic appendectomy in LT recipients is recently increased. As mentioned previously, earlier studies report on acute appendicitis managed in the open approach (Table 4). In 2012, Quartey et al. ${ }^{4}$ reported the first laparoscopic appendectomy case in a LT patient. Followed by this report, Wei et al. ${ }^{15}$ reported two cases of laparoscopic appendectomy in a liver and kidney transplant recipients. Laparoscopic appendectomy was common in our study accounting for approximately $60 \%$ especially after 2015. There was only one case of open appendectomy after 2015 in which that patient received two laparotomies prior to appendectomy and thus, warranting the open approach due to safety issues.

This study includes the largest series of laparoscopic appendectomy in LT recipients. There was no intra or postoperative complications observed or documented. Furthermore, there was no significant difference in the operation time and postoperative hospitalization days between open and laparoscopic appendectomy $(p>0.05)$. Therefore, laparoscopic appendectomy can be considered safe and can be a better choice in selected patients. The placement of intra-abdominal drains in patients undergoing appendectomy has always been controversial. However, in cases with perforation or formation of periappendiceal abscesses, drain placements are recommended.

Most pathological findings were acute suppurative appendicitis, there was a single case of perforation. The patient was admitted to the emergency department with septic shock and during the operation, intra-abdominal spillage and contamination was observed. There was no postoperative complication and the patient was discharged after seven days (Case 6). Although periappendiceal abscess formation is reported to be rare in transplant recipients, ${ }^{15}$ there were three cases of abscess formation. All three patients underwent laparoscopic appendectomy and were discharged without complications. Moreover, there was one patient diagnosed with HCC metastasis (Case 5). There was no postoperative complication and was discharged on postoperative day four. However, the patient died due to the progression of hepatocellular carcinoma. 
One of the interesting findings in this study is that one patient was diagnosed with low-grade appendiceal mucinous neoplasm (Case 9). There has been no report on appendiceal mucinous neoplasm diagnosed in a LT patient. The patient presented with abdominal discomfort accompanied by fever, general weakness, nausea, vomiting and diarrhea. Upon admission to the emergency department, CT scans were taken and showed appendiceal distension with mild wall thickening. The patient was diagnosed with acute appendicitis and underwent laparoscopic appendectomy. During the surgery, a mildly edematous appendix without further complications was observed. However, the patient was diagnosed with appendiceal mucinous neoplasm on the final pathologic report. The patient was discharged on postoperative day 11 with the longest postoperative hospitalization but without any complications during postoperative care.

The median postoperative length of stay was four days with no postoperative complications and mortality. There was no acute graft rejection or failure observed in these patients. All of our patients recovered well with proper liver function and no sign of acute rejection.

In conclusion, with increased number of liver transplantation and overall survival of these patients, the incidence of acute appendicitis in post-LT patients is increasing. Surgeons must be more cautious in recognizing, making a diagnosis and treating acute appendicitis in LT recipients. The incidence of appendicitis in post-LT patients is up to $0.5 \%$. Laparoscopic appendectomy can be performed safely for treatment of acute appendicitis in post-LT patients.

\section{ORCID}

Indah Jamtani: https://orcid.org/0000-0002-4809-0063

Sara Kim: https://orcid.org/0000-0001-7829-1977

Jeong-Moo Lee: https://orcid.org/0000-0001-7806-8759

Kwang-Woong Lee: https://orcid.org/0000-0001-6412-1926

Suk Kyun Hong: https://orcid.org/0000-0002-0020-6215

Kwangpyo Hong: https://orcid.org/0000-0001-7909-8116

Eui Soo Han: https://orcid.org/0000-0001-9582-1255

Nam-Joon Yi: https://orcid.org/0000-0002-5467-425X

Kyung-Suk Suh: https://orcid.org/0000-0002-9535-7349

\section{AUTHOR CONTRIBUTIONS}

Conceptualization: JML. Data curation: IJ, SK . Formal analysis: IJ, SK. Methodology: JML, SKH, KH, ESH. Project administration: JML, KWL. Visualization: IJ, SK, JML. Writing - originaldraft: IJ, SK. Writing - review \&amp; editing: JML, KSS, NJY, KWL.

\section{REFERENCES}

1. Fonseca-Neto OC, Lima HC, Melo PS, Lemos R, Leitão L, Amorim AG, et al. Acute apendicitis in liver transplant recipients. Arq Bras Cir Dig 2016;29:30-32.

2. Sheppard SE, Marecki HL, Psoinos CM, Movahedi B, Furman MJ, Bozorgzadeh A, et al. Acute appendicitis after liver transplantation: a case report and review of the literature. Int J Organ Transplant Med 2017;8:208-212.

3. Wu L, Zhang J, Guo Z, Tai Q, He X, Ju W, et al. Diagnosis and treatment of acute appendicitis after orthotopic liver transplant in adults. Exp Clin Transplant 2011;9:113-117.

4. Quartey B, Dunne J, Cryer C. Acute appendicitis post liver transplant: a case report and literature review. Exp Clin Transplant 2012;10:183-185.

5. Abt PL, Abdullah I, Korenda K, Frank A, Peterman H, Stephenson GR, et al. Appendicitis among liver transplant recipients. Liver Transpl 2005;11:1282-1284.

6. Savar A, Hiatt JR, Busuttil RW. Acute appendicitis after solid organ transplantation. Clin Transplant 2006;20:78-80.

7. Wu JM, Lin HF, Chen KH, Tseng LM, Tsai MS, Huang SH. Impact of previous abdominal surgery on laparoscopic appendectomy for acute appendicitis. Surg Endosc 2007;21:570-573.

8. Curet MJ. Special problems in laparoscopic surgery. Previous abdominal surgery, obesity, and pregnancy. Surg Clin North Am 2000;80:1093-1110.

9. Lee SG, Moon DB, Hwang S, Ahn CS, Kim KH, Song GW, et al. Liver transplantation in Korea: past, present, and future. Transplant Proc 2015;47:705-708.

10. de'Angelis N, Esposito F, Memeo R, Lizzi V, Martìnez-Pérez A, Landi F, et al. Emergency abdominal surgery after solid organ transplantation: a systematic review. World J Emerg Surg 2016; $11: 43$.

11. Ceulemans P, Wybaillie E, Monbaliu D, Aerts R, Pirenne J. Acute appendicitis after liver transplantation: a case report and review of the literature. Acta Chir Belg 2010;110:335-338.

12. Huang JF, Ma JF, Gong Y, Yu LL, Cui CX, Yang LX, et al. Acute appendicitis in the early stage after orthotopic liver transplantation. Chin Med J (Engl) 2017;130:1253-1254.

13. Ince V, Barut B, Ozdemir F, Ersan V, Kutluturk K, Gonultas $\mathrm{F}$, et al. The management of acute appendicitis in liver transplant patients: how effective is the Alvarado score? North Clin Istanb 2017;4:262-266.

14. Andrade RO, Pires RS, Silva RÉ, Mello FPT, Sousa CCT, Basto ST, et al. Acute appendicitis after liver transplant: a case report and review of the literature. Open J Organ Transpl Surg 2014;4: 29-32.

15. Wei CK, Chang CM, Lee $\mathrm{CH}$, Chen JH, Yin WY. Acute appendicitis in organ transplantation patients: a report of two cases and a literature review. Ann Transplant 2014;19:248-252.

16. Di Saverio S, Birindelli A, Kelly MD, Catena F, Weber DG, Sartelli M, et al. WSES Jerusalem guidelines for diagnosis and 
treatment of acute appendicitis. World J Emerg Surg 2016;11:34.

17. Rodrigues FG, Dasilva G, Wexner SD. Neutropenic enterocolitis. World J Gastroenterol 2017;23:42-47.

18. Stroman DL, Bayouth CV, Kuhn JA, Westmoreland M, Jones $\mathrm{RC}$, Fisher TL, et al. The role of computed tomography in the diagnosis of acute appendicitis. Am J Surg 1999;178:485-489. 19. Drake FT, Mottey NE, Farrokhi ET, Florence MG, Johnson MG, Mock $\mathrm{C}$, et al. Time to appendectomy and risk of perforation in acute appendicitis. JAMA Surg 2014;149:837-844. 